\title{
An Evaluation of Selection for Volume Growth in Loblolly Pine
}

\author{
By J. R. Sherrill ${ }^{1)}$, T. J. Mullin ${ }^{2)}$, B. P. Bullock ${ }^{3)}$, \\ S. E. McKeand ${ }^{3)}$, R. C. Purnell ${ }^{4)}$, M. L. Gumpertz' ${ }^{5)}$ and F. IsIK ${ }^{3)}$
}

(Received $9^{\text {th }}$ September 2006)

\begin{abstract}
Total inside-bark volume is the most important selection criterion for productivity in tree breeding programs in the Southeastern U.S. Tree breeders typically estimate total inside-bark volume based on outside-bark diameter at breast height and total height without accounting for stem taper or bark thickness. To make a direct determination of total inside- and outside-bark volume, a loblolly pine (Pinus taeda L.) open-pollinated family trial replicated with cultural treatments of weed control and fertilization was measured. This direct measurement was compared to typical volume estimates. In this trial, approximately 40 individuals from each of 25 open-pollinated first- and second-generation families were destructively sampled in the $13^{\text {th }}$ growing season.

Selection for volume using a combined-variable (diameter $^{2} *$ height) equation was found to be highly effective for making volume gain. There was a high correlation between estimated and directly-measured total insidebark volumes (0.99). Bark thickness and stem taper had low importance for stem volume selection. There was a positive genetic correlation between bark thickness and diameter at breast height (0.66). This indicates that selection for larger diameters may produce individuals with thicker bark, which may eventually affect total inside-bark volume estimates.
\end{abstract}

Key words: bark thickness, genotype by treatment interaction, stem taper, volume gain, Pinus taeda L., stem volume, tree improvement, stem form.

\section{Introduction}

Many tree breeding programs around the world select for stem size more than any other trait. Numerous programs estimate volume using a combined-variable equation that uses outside-bark diameter (D) at breast height $(\mathrm{BH})$ (measured $1.37 \mathrm{~m}$ above the ground level) squared and multiplied by total tree height $(\mathrm{H})$ as a regressor on inside-bark volume. Total inside-bark stem volume is difficult to assess directly from standing trees, so selection on estimated volume may be considered a form of indirect selection.

1) Corresponding Author, Rayonier, P.O. Box 819, Yulee, FL 32041, USA, Phone: 904-225-5393, Fax: 904-225-0370, e-mail: josh.sherrill@rayonier.com.

2) BioSylve Forest Science NZ Limited, 58 Huntington Dr, Hamilton 3210, New Zealand.

3) Department of Forestry and Environmental Resources, North Carolina State University, Campus Box 8002, Raleigh, NC 27695-8002, USA.

4) Genetics Research, Weyerhaeuser Co., 810 Whittington Ave, Hot Springs, AR 71901, USA.

5) Department of Statistics, North Carolina State University, Campus Box 8203, Raleigh, NC 27695-8203, USA.
The North Carolina State University - Industry Cooperative Tree Improvement Program has a long history using the GOEBEL and WARNER (1966) combined-variable equation (Goebel-Warner equation). The Goebel-Warner equation was derived by least-squares regression using data from 74 loblolly pine trees from the upper South Carolina Piedmont. Combined-variable equations have been effective in fitting prediction equations for total inside-bark volume to small datasets (SPURR, 1952). More robust combined-variable equations could be created from more than 74 stems across many diverse sites. Regardless of the source of the data, combined-variable equations do not account for differences in stem taper and bark thickness at $\mathrm{BH}$ among individuals or families. This is a matter of some concern to breeders.

There are only a few studies looking at genetic variation in stem taper in loblolly pine. No difference in stem taper between unrogued and rogued first-generation open-pollinated (OP) loblolly pine families planted operationally was found by BUFORD and BURKHART (1987). Likewise, PEDERICK (1970) did not detect any significant half-sib family differences for loblolly pine in inside-bark taper measurements and felt that diameter inside-bark (d.i.b.) at $\mathrm{BH}$ and total tree height could adequately predict wood volume. PEDERICK (1970) did find that bark thickness was more important than stem taper in progeny selection since estimated inside-bark volume calculated from $\mathrm{D}$ and $\mathrm{H}$ could be over- or under-estimated by $3.3 \%$ due to bark thickness. He also found a positive genetic correlation between bark thickness and d.i.b. growth $\left(r_{g}=0.66\right)$ after accounting for $D$, suggesting that selection for larger diameter growth may result in trees with thicker bark. PEDERICK (1970) estimated individual-tree narrow-sense heritability for bark thickness as 0.60. Similarly, MATZIRIS (2000) found that bark thickness and D were genetically correlated $(r=0.85)$ in Aleppo pine (Pinus halepensis Mill.) and estimated individual tree narrow-sense heritabilities for $\mathrm{BH}$ bark thickness as 0.15 and 0.24 on two different sites in Greece at age 10. IsIK et al. (1999) reported BH bark thickness narrow-sense heritabilities for individual trees as 0.04 and family-means as 0.11 in Pinus brutia Ten. for an age 17 trial in Turkey.

Presently, second-generation OP loblolly pine families have not been assessed for stem taper or bark thickness differences. The presence of stem-taper and bark-thickness differences among genotypes in a progeny trial could confound the differences in total inside-bark volume among individuals or OP families. Therefore, the objective of this study was to evaluate selection for total inside-bark volume with a combined-variable equation and to evaluate the estimated volume gain under different silvicultural treatments. 


\section{Materials and Methods}

A genotype by cultural treatment study at Bainbridge, GA, USA (latitude $30.903 \mathrm{~N}$ and longitude $84.575 \mathrm{~W}$ ) was destructively sampled in its $13^{\text {th }}$ growing season. The study was a split-plot design with five blocks. There were $25 \mathrm{OP}$ loblolly pine families arranged as 6-tree noncontiguous single-tree plots (subplots) in a randomized complete-block design. The number of families was restricted in the study design to minimize the withinblock environmental variation. Although a typical loblolly progeny tests contains 75 families, a population of 25 families was thought to be adequate for genetic parameter estimates.

The main plot was a two by two factorial of weed control and fertilization treatments for a total of four treatment plots. The weed control treatment consisted of early woody and herbaceous competition control for the first five years. All treatment plots were released with aerially applied herbicide at age five. The fertilization treatment consisted of 85 g per tree of 20-4-15 fertilizer applied twice at age one and $1121 \mathrm{~kg}$ per ha of 20-5-15 with micronutrients applied from the ground at ages four, five, and nine. The fertilization treatment was more aggressive than most operational stands and was expected to result in substantial increased stem volume growth.

Stem analysis of 985 trees determined total insidebark volume using outside-bark diameter and bark thickness measurements along the stem of the felled trees. The sampling target was two trees per family per treatment per block. Fifteen stems across nine families were dropped due to missing data.

Measurements were made at $0.2,0.6,1.4$, and $2.4 \mathrm{~m}$ heights above ground level, and every $1.2-\mathrm{m}$ thereafter to a $7.6 \mathrm{~cm}$ outside-bark top diameter. Smalian's log volume equation was used for each stem section below the $7.6 \mathrm{~cm}$ outside-bark top diameter and the volume formula for a conoid was used above the $7.6 \mathrm{~cm}$ outside-bark top to the stem's tip (AVERY and BURKHART, 2002). Volumes from each stem section were summed for a directly-measured whole-tree volume. In addition to diameter measurements, total height, height to live crown, and height to a $7.6 \mathrm{~cm}$ top diameter were measured. Total height and the outside-bark diameter at the $1.4 \mathrm{~m}$ height were used in estimating volume with the GoebelWarner equation and a combined-variable equation fit to the destructively sampled stem data.

\section{Volume estimation}

Volumes estimated from the Goebel-Warner equation (GOEBEL and WARNER, 1966) were compared with those determined by stem analysis of the felled tress. The Goebel-Warner equation converted to metric form is:

$$
\hat{V}_{i b}=0.954560899+0.282415876\left(\frac{D^{2} H}{10}\right)
$$

where $\hat{V}_{i b}$ is the estimated total inside-bark volume, $\mathrm{dm}^{3}$ and $D^{2} H$ is the combined variable term in $\mathrm{cm}^{2} * \mathrm{~m}$.

\section{Genetic parameters}

Variance components were estimated from the following linear mixed model

$$
Y_{i j k l}=\mu+B_{i}+T_{j}+B T_{i j}+F_{k}+F B_{j k}+F T_{j k}+F B T_{i j k}+\varepsilon_{i j k l}
$$

where $Y_{i j k l}$ is the trait of interest, $\mu$ is the overall mean, $B_{i}$ is the fixed block effect, $T_{j}$ is the fixed treatment effect (level of weed control and fertilization treatments), $B T_{i j}$ is the fixed block by treatment interaction, $F_{k}$ is the random family effect, normally and independently distributed with 0 mean and $\sigma_{\mathrm{f}}^{2}$ variance $(\mathrm{k}=1, \ldots, 25) ; F B_{i k}$ is the random family by block interaction, with 0 mean and $\sigma_{\mathrm{fb}}^{2}$ variance; $F T_{j k}$ is the random family by treatment interaction, with 0 mean and $\sigma_{\mathrm{ft}}^{2}$ variance; $F B T_{i j k}$ is the random family by block by treatment interaction, with 0 mean and $\sigma_{\text {fbt }}^{2}$ variance; and $\varepsilon_{i j k l}$ is the random tree-to-tree error with 0 mean and $\sigma^{2}$. The random effects were assumed to have a normal distribution and be independent of each other. The computer program, ASReml (GILMour et al., 2002) was used to estimate variance components and their corresponding standard errors. ASReml uses restricted maximum likelihood for fitting linear mixed models and estimating variance components and the delta method for calculating standard errors. There were some genetic relationships among OP families that were accounted for with a pedigree file in ASReml. To remove the confounding effect of tree size on bark thickness, variance components for bark thickness were estimated with insidebark diameter as a continuous regressor. Narrow-sense individual-tree heritability $\left(h_{i}^{2}\right)$ was estimated as the ratio of additive to phenotypic variance as follows.

$$
h_{i}^{2}=\frac{4 \sigma_{f}^{2}}{\sigma_{f}^{2}+\sigma_{f b}^{2}+\sigma_{f t}^{2}+\sigma_{f b t}^{2}+\sigma_{e}^{2}}
$$

Family-mean heritability estimates used coefficients from expected mean squares estimated in ASReml for the random family effect to adjust for imbalances in the dataset. Family-mean heritabilities were computed as

$$
h_{f}^{2}=\frac{\sigma_{f}^{2}}{\sigma_{f}^{2}+\frac{k_{2} \sigma_{f b}^{2}}{k_{1}}+\frac{k_{3} \sigma_{f t}^{2}}{k_{1}}+\frac{k_{4} \sigma_{f b t}^{2}}{k_{1}}+\frac{\sigma_{e}^{2}}{k_{1}}}
$$

where $h_{f}^{2}$ is the family-mean heritability, and $k_{1}$ to $k_{4}$ are the coefficients for $\sigma_{f}^{2}, \sigma_{f b}^{2}, \sigma_{f t}^{2}$ and $\sigma_{f b t}^{2}$, respectively, in the expected mean squares for $F$.

Values for several traits were transformed to increase the homogeneity of the error variances. The traits subjected to square root transformation were measured total inside-bark volume, measured total outside-bark volume, total inside-bark volume estimated with the Goebel-Warner equation, and $\mathrm{D}^{2} \mathrm{H}$ for the estimation of heritabilities and genetic correlations. Total height was squared for both the estimation of heritabilities and genetic correlations.

Genetic covariances and genetic correlations were estimated by fitting a bivariate model, solving, and estimating standard errors using ASReml (GILMOUR et al., 2002). The following genetic correlation equation given by FALCONER and MACKAY (1996) was used in the estimation:

$$
r_{G}=\frac{\operatorname{COV}(x y)}{\sqrt{\operatorname{VAR}(x)^{*} \operatorname{VAR}(y)}}
$$


where $r_{G}$ is the genetic correlation between traits $x$ and $y, \operatorname{COV}(x y)$ is the family covariance between traits $x$ and $y$, and $\operatorname{VAR}(x)$ and $\operatorname{VAR}(y)$ are the family variance components of traits $x$ and $y$, respectively.

\section{Evaluating selection for total volume}

Assuming the same selection intensity, the selection efficiency $(S)$ for estimated volume $(x)$ when the selection is based on measured volume $(y)$ was estimated as per (FALCONER and MACKAY, 1996):

$$
S=\frac{h_{x} r_{A}}{h_{y}}
$$

where $h_{x}$ is the square-root of the family-mean heritability of the estimated volume, $r_{A}$ is the genetic correlation between estimated volume and the measured volume, and $h_{y}$ is the square-root of the family-mean heritability of measured volume.

To evaluate the importance of family by treatment interaction, the average Type-B genetic correlation $\left(r_{G_{B}}\right)$ among treatments was calculated for each trait as

$$
r_{G_{B}}=\frac{\sigma_{\mathrm{A}}^{2}}{\sigma_{\mathrm{A}}^{2}+\sigma_{\mathrm{AT}}^{2}}
$$

where $\sigma_{\mathrm{A}}^{2}$ is the additive genetic variance and $\sigma_{\mathrm{AT}}^{2}$ is the additive genetic by treatment interaction variance. These correlations describe the interaction of the genotype with different environments (YAMADA, 1962). The error variance in each of the four treatments is assumed constant with this formula (BURDON, 1975). The error variance for each trait presented in this paper was made homogeneous through transformations. If the genotype by treatment interaction variance component is greater than half the size of the family variance component (Type-B correlation < 0.67) then the interaction is said to be large and important in tree improvement (SHELBOURNE, 1972).

The genetic correlation between bark thickness and D was estimated with bark thickness values adjusted for stem size. This adjustment was accomplished by regressing bark-thickness on inside-bark diameter and adding the individual residual values of inside-bark diameter to the bark-thickness grand mean. Analysis of variance was then performed on the adjusted bark thickness values. Phenotypic correlations were estimated similarly, but with the phenotypic covariance and variances as Pearson's correlation coefficient. This was done with the CORR procedure in SAS (SAS-INSTITUTE, 2004).

Crown ratio was estimated as the percentage of stem occupied by live crown:

$$
C R=\left(\frac{H-H_{L C}}{H}\right) 100
$$

where $C R$ is the crown ratio, $H$ is the total stem height, and $H_{L C}$ is the height to the base of the live crown.

Form quotients were calculated using the following equation:

$$
F Q=\left(\frac{d_{h 1}}{d_{h 2}}\right)
$$

where $F Q$ is the form quotient, $d_{h 1}$ is the diameter at height 1 , and $d_{h 2}$ is the diameter at height 2. Pairs of heights where diameters were used to estimate form quotients were $4.9 \mathrm{~m}$ and $1.4 \mathrm{~m}, 2.4$ and $0.6 \mathrm{~m}$, and 2.4 and $0.2 \mathrm{~m}$. Two form quotients were estimated for each set of heights, one with inside-bark diameters and the other with outside-bark diameters. These form quotients were created in an attempt to represent stem form in short stems where as most form quotients are used on much larger trees at rotation age.

A regression coefficient (slope) $\left(\beta_{1}\right)$ from a stem-taper regression on each individual stem was used to estimate genetic parameters. This was developed by the authors as an indicator of average stem taper. The taper equation fit to each stem was

$$
d^{2}=\beta_{0}+\beta_{1} h+\varepsilon
$$

where $d$ is the inside-bark diameter measured $(\mathrm{cm}), h$ is the height $(\mathrm{m})$ above ground line at which $d$ was measured, $\beta_{0}$ and $\beta_{1}$ are parameters to be estimated, and $\varepsilon$ is the error term.

\section{Evaluating accuracy of volume estimates}

The range in family-mean percent deviations (MPD) (PEDERICK, 1970) were used to compare the GoebelWarner equation (GOEBEL and WARNER, 1966) and a $\mathrm{D}^{2} \mathrm{H}$ equation fit to the data from the destructive sample. The formula for MPD was

$$
\overline{M P D}_{k}=\frac{\left(\sum_{n=1}^{k} \frac{\hat{V}_{i b}-V_{i b}}{V_{i b}}\right) 100}{n}
$$

where $\hat{V}_{i b}$ is the predicted total inside-bark volume for individual stems of family $k, V_{i b}$ is the measured total inside-bark volume for individual stems of family $k$, and $\overline{M P D}_{k}$ is the mean percent deviation for family $k$ with $n$ stems.

\section{Results}

Descriptive statistics for the data used in this research are presented in Table 1. A mixed model analysis was used to find the significance of fixed treatment effects and the relative importance of random family effects. The analysis revealed statistically significant effects of weed control $(p=0.0218)$ and fertilization $(\mathrm{p}=0.0045)$ on measured inside-bark volume with little genotype by treatment interactions (SHERRILL, 2005).

\section{Genetic parameters}

Narrow-sense individual-tree heritabilities for growth traits varied from 0.03 (taper coefficient) to 0.27 (estimated i.b. volume, $\mathrm{D}^{2} \mathrm{H}$, and D) (Table 2). Half-sib family-mean heritabilities varied from 0.19 (taper coefficient) to 0.72 (estimated volume (i.b.), $\mathrm{D}^{2} \mathrm{H}$, and $\mathrm{D}$ ) (Table 2). The heritability of bark thickness was 0.21 for individual-tree and 0.62 for family-mean after accounting for d.i.b. at BH. Crown ratio, the taper coefficient, and several of the form quotients had relatively low heritabilities. The outside-bark form quotients with diameters at 2.4 and $0.6 \mathrm{~m}$ and 2.4 and $0.2 \mathrm{~m}$ had the highest estimated heritability among the form quotients. 
Table 1. - The overall means with standard deviation in parentheses for all four cultural treatments.

\begin{tabular}{lcccc}
\hline Traits & Control & Herbicide & Fertilizer & $\begin{array}{c}\text { Herbicide and } \\
\text { Fertilizer }\end{array}$ \\
\hline Total volume (i.b.) $\left(\mathrm{m}^{3}\right)$ & $0.07(0.04)$ & $0.09(0.04)$ & $0.09(0.05)$ & $0.13(0.05)$ \\
D $(\mathrm{cm})$ & $14.6(3.4)$ & $16.0(3.3)$ & $16.8(3.6)$ & $18.6(3.2)$ \\
Bark thickness at BH $(\mathrm{cm})$ & $1.4(0.3)$ & $1.4(0.3)$ & $1.5(0.3)$ & $1.5(0.3)$ \\
H $(\mathrm{m})$ & $11.9(1.7)$ & $13.0(1.8)$ & $12.3(1.5)$ & $14.0(1.4)$ \\
Crown Ratio & $62.9(6.9)$ & $59.5(8.0)$ & $60.8(7.7)$ & $56.5(7.4)$ \\
Sample size & 249 & 250 & 245 & 241 \\
\hline
\end{tabular}

Where i.b. = inside-bark, $\mathrm{D}=$ diameter at breast height, $\mathrm{H}=$ total stem height, $\mathrm{BH}=$ breast height.

Table 2. - Individual tree $\left(h_{i}^{2}\right)$ heritability, half-sib family-mean $\left(h_{f}^{2}\right)$ heritability, and average Type B genetic correlation $\left(r_{G_{B}}\right)$ for 16 traits across four treatments (standard errors in parentheses).

\begin{tabular}{lccccc}
\hline Trait & \multicolumn{2}{c}{$h_{i}^{2}$} & \multicolumn{2}{c}{$h_{f}^{2}$} & $r_{G_{B}}$ \\
\hline Total volume (i.b.) & 0.24 & $(0.10)$ & 0.69 & $(0.10)$ & $0.84(0.23)$ \\
Total volume (o.b.) & 0.26 & $(0.10)$ & 0.71 & $(0.10)$ & $0.86(0.22)$ \\
Estimated volume (i.b.) & 0.27 & $(0.10)$ & 0.72 & $(0.09)$ & $0.90(0.22)$ \\
D $^{2} \mathrm{H}$ & 0.27 & $(0.10)$ & 0.72 & $(0.09)$ & $0.90(0.22)$ \\
D & 0.27 & $(0.10)$ & 0.72 & $(0.09)$ & $0.87(0.21)$ \\
Diameter (.i.b.) at BH & 0.24 & $(0.10)$ & 0.69 & $(0.10)$ & $0.91(0.25)$ \\
Adjusted BH bark thickness & 0.21 & $(0.09)$ & 0.62 & $(0.12)$ & $1.00(0.00)$ \\
H & 0.19 & $(0.08)$ & 0.65 & $(0.10)$ & $1.00(0.00)$ \\
Crown Ratio & 0.06 & $(0.06)$ & 0.32 & $(0.23)$ & $0.42(0.37)$ \\
Form quotient (i.b., $2.4 \mathrm{~m} / 0.6 \mathrm{~m})$ & 0.15 & $(0.08)$ & 0.55 & $(0.15)$ & $0.75(0.35)$ \\
Form quotient (o.b., 2.4m/0.6m) & 0.17 & $(0.08)$ & 0.60 & $(0.13)$ & $0.79(0.31)$ \\
Form quotient (i.b., 2.4m/0.2m) & 0.06 & $(0.06)$ & 0.30 & $(0.24)$ & $0.45(0.44)$ \\
Form quotient (o.b., 2.4m/0.2m) & 0.17 & $(0.09)$ & 0.59 & $(0.14)$ & $0.71(0.27)$ \\
Form quotient (i.b., 4.9m/BH) & 0.09 & $(0.06)$ & 0.47 & $(0.19)$ & $0.92(0.65)$ \\
Form quotient (o.b., 4.9m/BH) & 0.11 & $(0.06)$ & 0.50 & $(0.16)$ & $1.00(0.00)$ \\
Taper coefficient & 0.03 & $(0.05)$ & 0.19 & $(0.28)$ & $0.40(0.68)$ \\
\hline
\end{tabular}

Table 3. - Genetic correlations \pm standard error (above the diagonal) and phenotypic correlations (below the diagonal) between pairs of traits. Only relevant correlations are presented.

\begin{tabular}{|c|c|c|c|c|c|c|c|c|c|c|}
\hline & $\begin{array}{c}\text { Measured } \\
\text { Total } \\
\text { Volume } \\
\text { (i.b.) }\end{array}$ & $\begin{array}{c}\text { Measured } \\
\text { total } \\
\text { volume } \\
\text { (o.b.) }\end{array}$ & $\mathrm{D}^{2} \mathrm{H}$ & $\mathrm{D}$ & $\begin{array}{c}\text { d.i.b. at } \\
\text { BH }\end{array}$ & $\begin{array}{l}\text { Adjusted } \\
\text { BH bark } \\
\text { thickness }\end{array}$ & $\begin{array}{l}\text { Estimated } \\
\text { total } \\
\text { volume } \\
\text { (i.b.) }\end{array}$ & $\begin{array}{c}\text { Crown } \\
\text { Ratio }\end{array}$ & $\mathrm{H}$ & $\begin{array}{c}\text { Taper } \\
\text { coefficient }\end{array}$ \\
\hline Measured total volume (i.b.) & & & $0.99 \pm .01$ & & & & $0.99 \pm .01$ & $0.51 \pm .27$ & & \\
\hline Measured total volume (o.b.) & & & $1.00 \pm .00$ & & & & & $0.48 \pm .28$ & & \\
\hline $\mathrm{D}^{2} \mathrm{H}$ & $0.98 *$ & $0.99 *$ & & & & & & & & \\
\hline $\mathrm{D}$ & & & & & $0.99 \pm .00$ & $0.66 \pm .19$ & & & $0.77 \pm .12$ & \\
\hline d.i.b. at $\mathrm{BH}$ & & & & $0.99 *$ & & & & & & \\
\hline Adjusted BH bark thickness & & & & $0.15^{*}$ & & & & & & \\
\hline Estimated total volume (i.b.) & $0.98^{*}$ & & & & & & & & & \\
\hline Crown Ratio & 0.00 & 0.01 & & & & & & & $0.61 \pm .28$ & $0.52 \pm .46$ \\
\hline $\mathrm{H}$ & & & & $0.75^{*}$ & & & & $-0.11^{*}$ & & \\
\hline Taper coefficient & & & & & & & & $-0.08 *$ & & \\
\hline
\end{tabular}

* These phenotypic correlations were statistically significant at $\mathrm{P}=0.05$ significance level.

d.i.b. is diameter inside bark.

Genotype by treatment interactions were generally low as shown by high Type-B genetic correlations, indicating consistent ranking of half-sib families from one treatment to another for most traits (Table 2). Family by treatment interactions were larger for crown ratio, taper coefficient, and one form quotient (calculated with inside-bark diameters at 2.4 and $0.2 \mathrm{~m}$ ). These had Type-B genetic correlations less than 0.67 (Table 2). 
Genetic correlations of interest are given in Table 3 . As expected, estimated total inside-bark volume and $\mathrm{D}^{2} \mathrm{H}$ were both highly correlated with the measured total inside-bark volume from destructive sampling. Bark thickness adjusted for inside-bark diameter had a genetic correlation of 0.66 with $\mathrm{D}$. Crown ratio had low phenotypic and genetic correlation with almost every trait measured, except for a moderate positive genetic correlation with total height.

\section{Evaluating Selection for Total Volume}

Indirect selection for true total inside-bark volume using the total inside-bark volume given by the GoebelWarner equation was efficient as shown by high estimated selection efficiency of 1.01. This value was a result of the high genetic correlation (0.99) between estimated and measured total inside-bark volumes (Table 3).

Comparing the predicted line for the Goebel-Warner equation to the prediction line fit to the measured inside-bark volume in this study indicated that the intercepts of the two lines were similar, but the slopes are noticeably different (Figure 1).

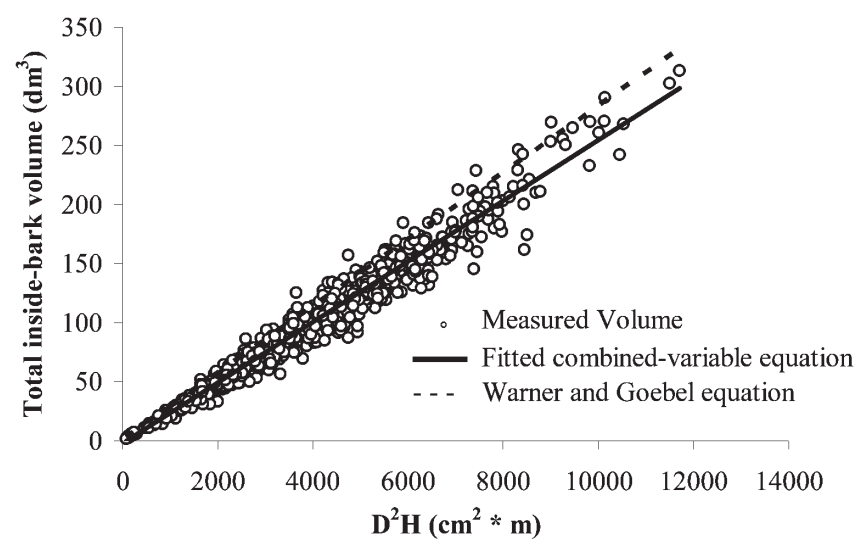

Figure 1. - Comparison of prediction lines for estimated and measured inside-bark volumes from the Goebel-Warner equation (eq. 1) and the fitted combined variable equation, respectively.

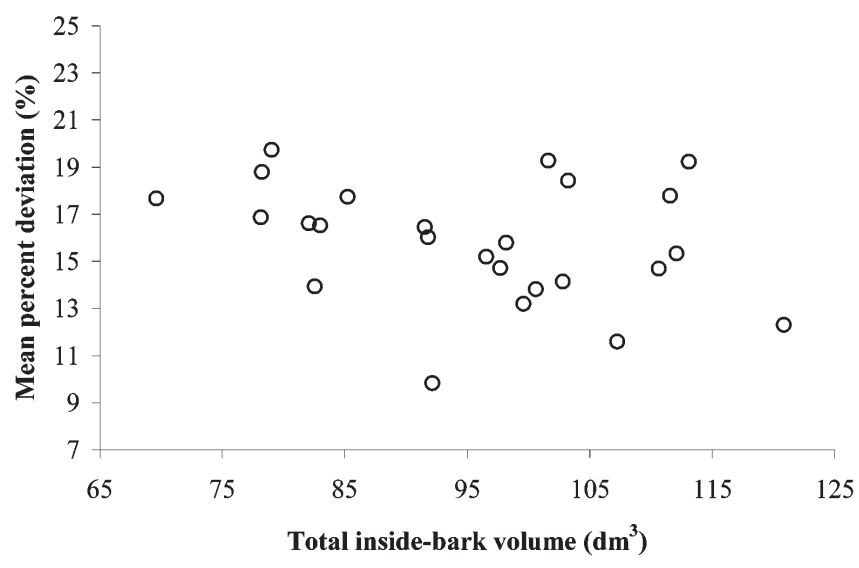

Figure 2. - The mean percent deviations between the GoebelWarner equation and measured inside-bark total volume for the 25 OP family means.

\section{Evaluating accuracy of volume estimates}

Fitting a combined-variable equation to the study dataset resulted in family MPDs that varied from -4.9 to $4.4 \%$. This range in MPD of $9.4 \%$ was similar to the range of MPDs from the Goebel-Warner equation (9.9\%).

There was overall bias associated with using the Goebel-Warner equation. The values of family MPDs from the Goebel-Warner combined-variable equation varied from 9.8 to $19.7 \%$ (Figure 2), which indicates upward bias. In Figure 2, there appeared to be no systematic deviation for any particular size of stems.

\section{Discussion}

\section{Genetic parameters}

Many of the growth traits (measured volume, H, D, etc.) had heritabilities comparable to those reported previously for growth traits in loblolly pine (SvENSSON et al., 1999; Sierra-LuCERo et al., 2002). Bark thickness at breast height had heritability estimates similar to those of many other growth traits after accounting for the size of the stem, indicating that bark thickness is under similar levels of genetic control as many growth traits. The heritability estimates for crown ratio and the taper coefficient were lower, suggesting substantial environmental effects on these traits. The stand condition effects on crown ratio have been shown to be important (LARSON, 1963; NEWBERRY and BURKHART, 1986). The resulting stand conditions from the silvicultural treatments could have influenced the crown ratio much more than the genetic effects. The heritability estimates for form-quotient traits varied dramatically. Form quotients involving inside-bark diameters had lower heritabilities than their outside-bark counterparts. This phenomenon was likely a result of increased error associated with additional traits, i.e., inside-bark diameters involved variation associated with outside-bark diameter and bark thickness measurements. The form quotients with outside-bark diameters at 2.4 and $0.6 \mathrm{~m}$ and at $2.4 \mathrm{~m}$ and $0.2 \mathrm{~m}$ had the highest heritabilities of the form quotients calculated. It is probable that the stump-height diameter measurement involved butt swell (inflated diameter growth at the base of the stem) variation in 13-year-old loblolly pine, and this could have reduced the heritability estimate for this form quotient.

Crown ratio had a low genetic correlation with most of the traits evaluated; the strongest positive genetic correlation was with height (Table 3). This indicates that selection for height will result in a higher percent live crown, which could lower the value for quality wood products because of more persistent branches. However, this finding could have been deceptive because of differences in stand conditions between a genetic test and the deployment of family blocks. The authors theorize if genetic tests have more variation in total height (and crown ratio) than family-block plantings, a family that performs well in height growth might reach crown closure earlier and develop a lower live crown ratio in family-block plantings.

Phenotypic correlation between crown ratio and the taper coefficient was negligible. This was contrary to 
many other reports (BALDWIN et al., 2000; LARSON, 1963; NEWBERRY and BURKHART, 1986), possibly because of stand condition or method differences between the present study and others. The main method differences could have been the variables used to describe stem taper.

\section{Evaluating selection for total volume}

Selection for true inside-bark volume by estimating volume with a combined-variable equation has been an effective practice based on selection efficiency. This high selection efficiency may have resulted from less error variance being associated with estimated volume than with the detailed volume measurement. The measured volume may have had more error variance due to variation in stem taper, bark thickness, environmental variation, and unknown factors. Nonetheless, D and H measurements captured a great deal of the genetic variation in total inside-bark volume. Differences in volume not accounted for by estimating volume with the combinedvariable equation were small enough for indirect selection to be effective. One caution about volume selection is that environmental effects are only somewhat controlled in field trials and therefore, stem size and competition effects can influence perceived significance of genetic growth differences (MAGNUSSEN, 1995). Reductions in block size with single-tree plots and alpha-lattice designs reduce environmental variation but it can not be eliminated.

Thicker bark results from selection of higher volume families due to a positive genetic correlation of bark thickness and diameter in loblolly pine. The genetic correlation of $\mathrm{D}$ and bark thickness was similar to the findings of PEDERICK (1970) where the correlation between bark thickness and d.i.b. at $\mathrm{BH}$ was estimated as 0.66 . Thicker bark could be an important defense against disease, insect, mechanical damage, and fire resistance (LoEHLE and NAMKOONG, 1987) but no commercial value has been explored. In fact, thicker bark individuals may result in slightly increased transportation and processing cost. The largest effect from the correlation of bark thickness and D may be from a biometrical standpoint. Bark thickness variation can confound d.i.b. at $\mathrm{BH}$ and increase the error associated with volume estimation and forecasting. This would indicate that updated models may be needed in future generations of breeding to prevent overestimation of wood volume for the genetic material that is being characterized. The bark thickness variation probably has a minimal effect on current estimates as indicated by the high correlation between estimated and measured total inside-bark volume.

Genotype by treatment interaction was noticeable only for crown ratio, the taper coefficient, and one form quotient (Table 2). Crown ratio was highly influenced by stand conditions related to silvicultural treatments (LARSON, 1963). Treatment had a relatively minor effect on the variability among genotypes in volume production. This indicates that genotype deployment and silvicultural treatments do not have to be coordinated to maximize total inside-bark volume. This finding is similar to the stability across environments described by McKeAnd et al. (2006) for loblolly pine. Stem taper could be a trait selected in future tree-breeding programs. The taper coefficient heritability was low for the taper model, but most form quotients had moderate heritability estimates. This indicates the average taper over the stem did not have a strong genetic component, but there was a strong genetic component for taper in some stem sections. Since the form quotients were calculated at fixed heights, stem size may have had an impact on the taper for the respective stem section. For example, two stems with different heights and diameters and the same age may have different ratios of diameters at 4.9 $\mathrm{m}$ and $\mathrm{BH}$, but have the same relative stem profile. The relative heights of these measurements may be misleading. Stem taper and crown ratio would probably not be easily selected as a pair of traits because crown ratio was not genetically correlated with stem taper. Other quality traits are probably more important in value than stem taper, such as forking or straightness, although it may have some economic value for producing solid wood products.

\section{Evaluating accuracy of volume estimates}

The difference in slopes between the Goebel-Warner equation and one fit to the study dataset demonstrates that the Goebel-Warner equation inflated the volumes of larger stems proportionally more than smaller stems (Figure 1). The trees used to derive the Goebel-Warner equation were from different genetic populations, with different soil characteristics, and different ages than the data in the present study. Using an equation that was fit to the specific dataset reduced the range in family MPDs from 9.9 to $9.4 \%$ and the standard deviation from 2.5 to $2.3 \%$. This minor change in MPD suggests two conclusions. The first conclusion is both equations were similar in precision. For selection and gain estimation purposes, overall precision is more important than overall bias because individuals or groups of individuals are being compared. The second conclusion is that locallyderived volume equations were not necessary in estimating volume for genetic trials. It is still recommended that local volume equations be used in genetic tests for similar age material in like environments, when available. Deriving volume equations for the sole purpose of local genetic trials is probably not cost-effective in a tree-breeding situation with trials spread over large geographic areas. The spread of family MPD values was reasonably constant over the range of measured insidebark volumes indicating no major relationship between family rank and the ability to accurately predict volume.

\section{Conclusions}

Indirect selection for estimated volume using the Goebel-Warner equation was effective to make gains in true inside-bark volume as indicated by high estimated selection efficiency. However, volume estimates for single OP families exhibited error that was probably related to small stem taper differences, small bark thickness differences, and random error. Using the combined-variable equation fit to the present dataset, individual families had mean volume estimates that deviated by as much as $5 \%$ from the measured value. 
Eventually, selection of fast growing families for volume may result in thicker bark due to a positive genetic correlation of bark thickness and D. Destructive samples may be required after future breeding cycles to create new volume prediction equations for operational plantations.

\section{Acknowledgements}

The authors would like to thank the North Carolina State University - Industry Cooperative Tree Improvement Program for financial support and International Paper Co. for the use of the study site. Special thanks go to Fred Haines, Richard Bryant, Steve Henry, Larry Stubbs, Daniel Gräns, Ben Smith and John Adams for assistance with data collection.

\section{References}

Avery, T. E. and H. E. BuRKHART (2002): Forest measurements. $5^{\text {th }}$ ed. McGraw-Hill. New York, N.Y. 456 p.

Baldwin JR., V. C., K. D. Peterson, A. Clark III, R. B. Ferguson, M. R. Strub and D. R. Bower (2000): The effects of spacing and thinning on stand and tree characteristics of 38-year-old loblolly pine. For. Ecol. and Manag. 137: 91-102.

BuFORD, M. A. and H. E. BurKharT (1987): Genetic improvement effects on growth and yield of loblolly pine plantations. For. Sci. 33: 707-724.

BuRdon, R. D. (1975): Compression wood in Pinus radiata clones on four different sites. N. Z. J. For. Sci. 5: 152-164.

FALCONER, D. S. and T. F. C. MACKAY (1996): Introduction to quantitative genetics. $4^{\text {th }}$ ed. Prentice Hall. Essex, England. $464 \mathrm{p}$.

Gilmour, A. R., B. J. Gogel, B. R. Cullis, S. J. Welham and R. Thompson (2002): ASReml User Guide Release 1.0. VSN International Ltd., Hemel Hempstead, UK.

GoebeL, N. B. and J. R. WARNER (1966): Volume tables for small diameter loblolly, shortleaf and Virginia pine in the upper South Carolina piedmont. Forest Research Series No. 7. Clemson University. Clemson, South Carolina.

ISIK, F., K. ISIK and S. J. LEE (1999): Genetic variation in Pinus brutia in Turkey: I. Growth, Biomass and Stem Quality Traits. For. Gene. 6: 89-99.
LARSON, P. R. (1963): Stem form development of forest trees. Vol. 5. Society of American Foresters. Washington, DC. $42 \mathrm{p}$.

LoeHLe, C. and G. NAmKoong (1987): Constraints on tree breeding: Growth tradeoffs, growth strategies, and defense investments. For. Sci. 33: 1089-1097.

McKeand, S. E., E. J. Jokela, D. A. Huber, T. D. Byram, H. Lee Allen, B. Li and T. J. Mullin (2006): Performance of improved genotypes of loblolly pine across different soils, climates, and silvicultural inputs. For. Ecol. and Manag. 227: 178-184.

MAGNussen, S. (1995): The impact of genetic variation in relative growth rates on stem volume differentiation: a simulation study. Silvae Genet. 44: 194-205.

MATZIRIS, D. I. (2000): Genetic variation and realized genetic gain from Aleppo pine tree improvement. Silvae Genet. 49: 5-10.

Newberry, J. D. and H. E. Burkhart (1986): Variableform stem profile models for loblolly pine. Can. J. For. Res. 16: 109-114.

PEDERICK, L. A. (1970): Variation and inheritance of stem form and bark thickness in young loblolly pine. Technical Report 41. School of Forest Resources, North Carolina State University. Raleigh, NC. 44 p.

SAS-InSTITUTE (2004): SAS Version 9 Cary, NC. SAS Institute, Inc.

ShelbouRne, C. J. A. (1972): Genotype-environment interaction: Its study and its implications in forest tree improvement. P. 1-28 in Proc. of IUFRO Genetics. Tokyo, Japan.

SHERRILL, J. R. (2005): Genetic and cultural effects on stem taper and bark thickness in loblolly pine (Pinus taeda L.). Ms Thesis. North Carolina State University, Raleigh, NC. 91p.

Sierra-Lucero, V., S. E. McKeand, D. A. Huber, D. L. Rockwood and T. L. White (2002): Performance differences and genetic parameters for four coastal provenances of loblolly pine in the Southeastern United States. For. Sci. 48: 732-742.

SpurR, S. H. (1952): Forest Inventory. Ronald Press Co. New York, NY. 476 p.

Svensson, J. C., S. E. McKeand, H. L. Allen and R. G. CAMPBELl (1999): Genetic variation in height and volume of loblolly pine open-pollinated families during canopy closure. Silvae Genet. 48: 204-207.

YAMADA, Y. (1962): Genotype by environment interaction and genetic correlation of the same trait under different environments. Jap. J. Genet. 37: 498-509. 